\title{
NATIONAL EFFICIENCY THROUGH HEALTH
}

\section{By Wilmer Krusen, M.D., \\ Direçtor Department of Public Health and Charities, Philadelphia.}

There are two great armies fighting in this conflict-one a military and naval force controlled largely by trained medical men in camp and cantonment, or overseas; the other, the greater from the numerical viewpoint, the civilian population, supervised and regulated by the health officers of our state and city departments. Our chief concern today is for our civilian population. We realize fully that health like charity begins at home.

May I first refer to the problems presented during this crisis and briefly to their solution. If the individual is healthful and efficient, then the community or municipality becomes safe and healthy unless sanitary surroundings are injurious and pernicious.

In Philadelphia the housing problem has become acute. The unexpected increase in our industrial population has found us unprepared. It is of vital importance that the home should be clean and sanitary. The water supply must be pure and adequate, the drainage perfect, and the sewage disposal adequate. This city must spend more money for the increase of its water supply and for the extension of its sewage system so that all cesspools may be abandoned without an exorbitant expense to the property owner. The housewife must have the sanitary conscience. There must be hearty and sympathetic coöperation between the civic official or agency and the citizen.

The keeping of live stock, such as chickens, goats and other animals, must be forbidden in the closely populated sections of a city. The "thirty years" war for the elimination of piggeries from the residential part of Philadelphia has resulted in a practical victory for the Health Department. The mosquito nuisance is now being actively combated in Philadelphia. The state and city departments are working with the federal authorities and much money will be expended this summer for the permanent elimination of this pest.

The control of communicable diseases is a constant battle,here "eternal vigilance" is the price of safety. In Philadelphia 
smallpox has been practically eliminated as a serious menace, but during the past few weeks we have had four sporadic cases; our typhoid record during 1917 was the lowest in the history of the city; tuberculosis has been reduced one half in the past thirty-five years.

A strict observance of quarantine rules and regard for the health of a neighbor's children are necessary to reduce the large number of contagious diseases in this city. One of the serious conditions which has perplexed the medical officers of the army and navy has been the many cases of contagious diseases which have occurred.

No lover of the human race or of his country can view with complacency the ravages of venereal diseases, nor fail to raise his voice in warning against them. Since January 1, the Health Department has tried to purify the stream, at the very source of its infection by the care and study of the unfortunates in the House of Correction. Clean living becomes a patriotic duty in war time as in no other period. The infected man becomes not only useless as a soldier, but a cost and a burden to the medical service of the nation, taking time and attention, medicine and money which rightfully belong to the soldier wounded in battle or sick with unavoidable disease incident to the congregating of men in camp and cantonment.

Our great industrial plants, our munition factories with their problems of chemical poisonings and occupational diseases demand scientific consideration. The health of the women workers-a subject which has been carefully studied in Great Britain - is now an American problem in a new sense. The effect of this industrial life upon the next generation must be remembered. Protective legislation must not be suspended or repealed, or we will suffer the consequences.

This is children's year in America, and the varied efforts to conserve infant life must be extended and financed. Prenatal care of mother, care of infant and child during pre-school age, is a theme we could discuss for hours. Let me urge intensive work and interest in this phase of health work.

War is a stimulus to effort not only of inventive genius for the destruction of life and the confusion of our enemies, but of constructive and beneficial genius for the conservation of life and the protection of health. We need only to mention the triumph of typhoid inoculation and the benefits of the Carrel-Dakin method of treating wounds as significant of progress in medical science. Medical men 
and students of sociology were rather startled by the announcement that twenty-nine per cent or nearly one-third of the young men of America between the ages of 21 and 31 were found physically unfit for military service. This emphasizes the necessity for routine physical examination for the discovery of incipient diseases or physical defects. It also emphasizes the value of a routine military service even for its physical benefit as well as its necessity for national protection in America today.

The solution of all of these problems rests in the hands of the educated and thoughtful people of America, who must see to it that those in the ignorant classes are given the necessary instruction either by medical men, nurses, or civic organizations in the principles of health and hygiene. Patriotic duty demands active coöperation with health authorities and obedience to rules and regulations which are the crystallized sentiment of the best scientific minds of the country. Education without health is useless, and education is far more useful than legislation. We have enough laws on our statute books to last for fifty years, but unless we realize that it is necessary to obey these laws and that health is a physiologic function of the community our efforts will be in vain.

\section{ELIMINATING VICE FROM CAMP CITIES}

By Major Bascom Johnson, Director Sanitary Corps, National Army.

The principles underlying and the reasons for the existence of a recreation program are well known to everyone. Every modern, up-to-date municipality has a playground system, and the people have become thoroughly familiar with the reasons why such a program ought to exist in every well-regulated city. The old maxim of "All work and no play makes Jack a dull boy," does not need much change to apply to the troops-that all drill and no recreation makes a pretty dull and, under certain environment, a pretty bad soldier. It seems hardly necessary, therefore, to dwell very much upon the recreation program of the Commission on Training Camp Activities. The program is well developed, is very comprehensive, and runs the gamut from athletic coaches and Liberty theaters 